\title{
Complications in CT-Guided, Semi-Automatic Coaxial Core Biopsy of Potentially Malignant Pulmonary Lesions
}

\section{Komplikationen bei CT gesteuerter, koaxialer Stanzbiopsie malignomverdächtiger Lungenherde in halbautomatischer Technik}

Authors

Affiliations
R. Schulze' , G. Seebacher ${ }^{2}$, B. Enderes², G. Kugler², J. R. Fischer ${ }^{3}$, T. P. Graeter ${ }^{2}$

Department of Radiology, Klinik Löwenstein, Löwenstein, Germany

Department of Thoracic and Vascular Surgery, Klinik Löwenstein, Löwenstein, Germany

3 Department of Oncology, Klinik Löwenstein, Löwenstein, Germany
Key words

- thorax

- percutaneous

- tissue characterization

- CT

- biopsy

received $\quad 8.1 .2015$

accepted $\quad 31.3 .2015$

Bibliography

DOI http://dx.doi.org/

10.1055/s-0034-1399648

Published online: 10.6.2015

Fortschr Röntgenstr 2015; 187 :

697-702 @ Georg Thieme

Verlag KG Stuttgart . New York .

ISSN 1438-9029

\section{Correspondence}

\section{Dr. Thomas Peter Graeter}

Department of Thoracic and Vascular Surgery, Klinik

Löwenstein

Gießhoelzle 62

74245 Löwenstein

Germany

Tel.: ++ 49/71 30/154203

Fax: ++49/71 30/154852

thomas.graeter@klinik-

loewenstein.de

\section{Abstract}

$\nabla$

Purpose: Histological verification of pulmonary lesions is important to ensure correct treatment. Computed tomographic (CT) transthoracic core biopsy is a well-established procedure for this. Comparison of available studies is difficult though, as technical and patient characteristics vary. Using a standardized biopsy technique, we evaluated our results for CT-guided coaxial core biopsy in a semi-automatic technique.

Materials and Methods: Within 2 years, 664 consecutive transpulmonary biopsies were analyzed retrospectively. All interventions were performed using a 17/18G semi-automatic core biopsy system ( 4 to 8 specimens). The incidence of complications and technical and patient-dependent risk factors were evaluated.

Results: Comparing the histology with the final diagnosis, the sensitivity was $96.3 \%$, and the specificity was $100 \% .24$ procedures were not diagnostic. In all others immunohistological staining was possible. The main complication was pneumothorax (PT, 21.7\%), with chest tube insertion in $6 \%$ of the procedures $(n=40)$. Bleeding without therapeutic consequences was seen in 43 patients. There was no patient mortality. The rate of PT with chest tube insertion was $9.6 \%$ in emphysema patients and $2.8 \%$ without emphysema $(p=0.001)$. Smokers with emphysema had a 5 times higher risk of developing PT $(p=0.001)$. Correlation of tumor size or biopsy angle and the risk of PT was not significant. The risk of developing a PT was associated with an increasing intrapulmonary depth of the lesion ( $\mathrm{p}=0.001)$.

Conclusion: CT-guided, semiautomatic coaxial core biopsy of the lung is a safe diagnostic procedure. The rate of major complications is low, and the sensitivity and specificity of the procedure are high. Smokers with emphysema are at a significantly higher risk of developing pneumothorax and should be monitored accordingly.

Key points:

- Using an 18G core biopsy system with 6 specimens will allow immunohistological staining with high sensitivity and specificity.

- Smokers with emphysema are at a significantly higher risk of developing a pneumothorax.

Citation Format:

- Schulze R, Seebacher G, Enderes B. etal. Complications in CT-Guided, Semi-Automatic Coaxial Core Biopsy of Potentially Malignant Pulmonary Lesions. Fortschr Röntgenstr 2015; 187: 697-702

\section{Zusammenfassung} $\nabla$

Ziel: Die histologische Sicherung eines malignomsuspekten Lungenherdbefundes ist die Grundvoraussetzung für eine adäquate Behandlung. Die computertomografische (CT), transthorakale Histologiesicherung ist dabei ein etabliertes Verfahren. Die Vergleichbarkeit der vorhandenen Studien ist aber schwierig, da sowohl technische Einflüsse als auch die Patientencharakteristika stark variieren. Unsere Ergebnisse nach CT-gesteuerter, koaxialer Stanzbiopsie in halbautomatischer Technik werden präsentiert.

Material und Methoden: 664 konsekutive Interventionen in einem 2-Jahres-Zeitraum wurden retrospektiv analysiert. Alle Eingriffe wurden mit einer halbautomatischen 17/18G Koaxialnadel durchgeführt, dabei 4-8 Proben entnommen. Komplikationsraten und der Einfluss technischer wie patientenabhängiger Risikofaktoren wurden analysiert. 
Ergebnisse: Bei Vergleich der histologischen Ergebnisse mit der endgültigen Diagnose lag die Sensitivität bei 96,3\%, die Spezifität bei $100 \% .24$ Untersuchungen waren nicht diagnostisch. In allen anderen Fällen wurde ausreichend Gewebe für eine immunhistologische Differenzierung gewonnen. Bei 21,7\% der Patienten $(n=144)$ zeigte sich ein Pneumothorax (PT), der in 6\% drainiert werden musste $(n=40)$. Bei 43 Patienten zeigte sich eine nicht interventionsbedürftige, selbstlimitierende Blutung. Die Letalität lag bei $0 \%$. Die drainagepflichtige PT-Rate bei Emphysempatienten betrug 9,6\%, ohne Empatienten 2,8\% ( $p=0,001)$. Die PT-Rate bei Rauchern mit Emphysem war 5fach erhöht $(p=0,001)$. Punktionswinkel und die Größe des Lungenherdes zeigten keine Korrelation mit der PT Inzidenz. Das PT-Risiko korrelierte mit zunehmender Länge der intrapulmonalen Punktionsstrecke $(p=0,001)$. Schlussfolgerung: Die CT-gesteuerte, koaxiale Punktion von Lungenherden in halbautomatischer Technik ist ein sicheres diagnostisches Verfahren. Die Rate an therapierelevanten Komplikationen ist niedrig, die Sensitivität und Spezifität hoch. Patienten mit Emphysem und Raucheranamnese haben ein deutlich erhöhtes Pneumothoraxrisiko und sollten entsprechend überwacht werden.

\section{Introduction}

Histological verification of pulmonary lesions suspicious for malignancy is a basic requirement for ensuring adequate treatment. Multiple diagnostic options are available: CTguided biopsy, bronchoscopy with transbronchial biopsy, or diagnostic surgical removal of the lesion. Primarily peripheral lesions are particularly suitable for CT-guided biopsy but central lesions can also be diagnosed. For more exact analysis, immunohistological examination of the tissue can be performed $[1,2]$. Bronchoscopy with transbronchial biopsy is an alternative method and is particularly suitable for central lesions or lesions with endobronchial tumor growth [3]. Diagnostic verification via surgical intervention in the form of atypical lung resection with frozen section analysis [4] is significantly more invasive.

Percutaneous puncture of pulmonary lesions is a wellknown procedure. The first report on this method appeared in 1828 [5]. Due to the high rate of hemoptysis and pneumothorax, this method was initially not able to become established even after the introduction of computed tomography $[6,7]$. Multiple punctures of the pleura and larger puncture needles are associated with a higher risk of pneumothorax but the diagnostic quality depends on the number of specimens acquired [8, 9]. It is difficult to compare the available studies since technical influences on puncture as well as patient characteristics vary greatly and the number of cases is usually low. The coaxial technique has made it possible since the mid-1990 s to obtain multiple core biopsies with a single puncture of the visceral pleura $[1,10]$. Under standardization of the technical procedure, the incidence of complications and risk factors after CT-guided, coaxial core biopsy of pulmonary lesions suspicious for malignancy were examined via a semiautomatic technique.

\section{Materials and Methods}

$\nabla$

A total of 664 consecutive thoracic interventions over a period of 2 years were examined in this study. The indication for CT-guided histological verification was determined in an interdisciplinary manner. The evaluation included all CT-guided biopsies used for the diagnostic clarification of lung parenchymal changes suspicious for malignancy $(n=572)$ and punctures with transpleural access of the pleura $(n=25)$, mediastinum $(n=42)$, or breast wall $(n=25)$. The data were analyzed retrospectively. $68.8 \%$ $(n=457)$ of patients were men and $31.2 \%(n=207)$ were women. The average age of the patients was 62.7 years ( $18-92$ years). $71.4 \%$ of patients $(n=474)$ were smokers. According to radiological criteria, 313 patients had pulmonary emphysema [11].

The exclusion criteria for CT-guided biopsy were pronounced COPD with bullous parenchymal changes and an FEV1 of less than $30 \%$ of the target value, severe pulmonary hypertension, and suspicion of a vascular anomaly or a hydatid cyst. Taking of a thrombocyte aggregation inhibitor was not an exclusion criterion but needed to be stopped at least 7 days prior to intervention and could be temporarily replaced by a low-molecular heparin as needed. In the case of regular taking of oral anticoagulants, the intervention was performed starting at a quick value of over $60 \%$ or an INR $\leq 1.4$. Moreover, thrombocyte count of more than 60 thousand $G / 1$ was required $[12,13]$. A central position of the lesion to be punctured was not an exclusion criterion. The principles of the Helsinki Declaration from 1975 were taken into consideration. The local ethics committee approved the follow-up examination and the presentation of the anonymized data.

Prior to every intervention, CT examination of the chest with contrast agent when possible was performed. Based on this preinterventional CT examination, the optimum access was determined. The planned puncture path was not always the shortest path since the visceral pleura only needed to be perforated once. For puncture with a 6-row CT device, an examination was performed with a sequence of 3 images with a layer thickness of $4 \mathrm{~mm}$ with breath triggering (constant inspiration position or expiration position) and the optimum access was marked on the skin. The puncture angle and the distance between the skin and pleura were measured. Local anesthesia of the puncture track to the parietal pleura was administered after extensive local disinfection and a small incision in the skin was made. A $17 \mathrm{G}$ coaxial needle was then advanced through this incision at the planned puncture angle to the parietal pleura. With the patient in the same breathing position as before, the location of the lesion was confirmed and the coaxial needle was further advanced to the edge under CT monitoring ( $\bullet$ Fig. 1). On average, 6 biopsy specimens (range: 4-8) were acquired in a fan-like manner via a semiautomatic 18G biopsy needle (U.S. Biopsy, Indiana, USA). The depth of penetration of the biopsy needle into the tumor was carefully adapted to the tumor size so that tissue situated behind the tumor was damaged to the least extent possible. The standard length of the coaxial needle was $10.5 \mathrm{~cm}$ and the penetration depth was $1.5 \mathrm{~cm}$. The penetration depth into the pulmonary lesion was adapted by pulling the biopsy needle back into the coaxial cannula. Perifocal bleeding 
was so rare that the targeted 6 biopsies were regularly able to be obtained. That number of biopsies was necessary for reliable immunohistological examination. The administration of sedatives was not necessary during all examinations and was also not desired because the patient would not have been able to follow the breathing commands. Antitussives were also not used during the study. The patient underwent 3 additional representative postinterventional CT scans at the level of the upper, the middle and the lower thoracic aperture with one sequence through the biopsy plane being used to rule out a pneumothorax or significant

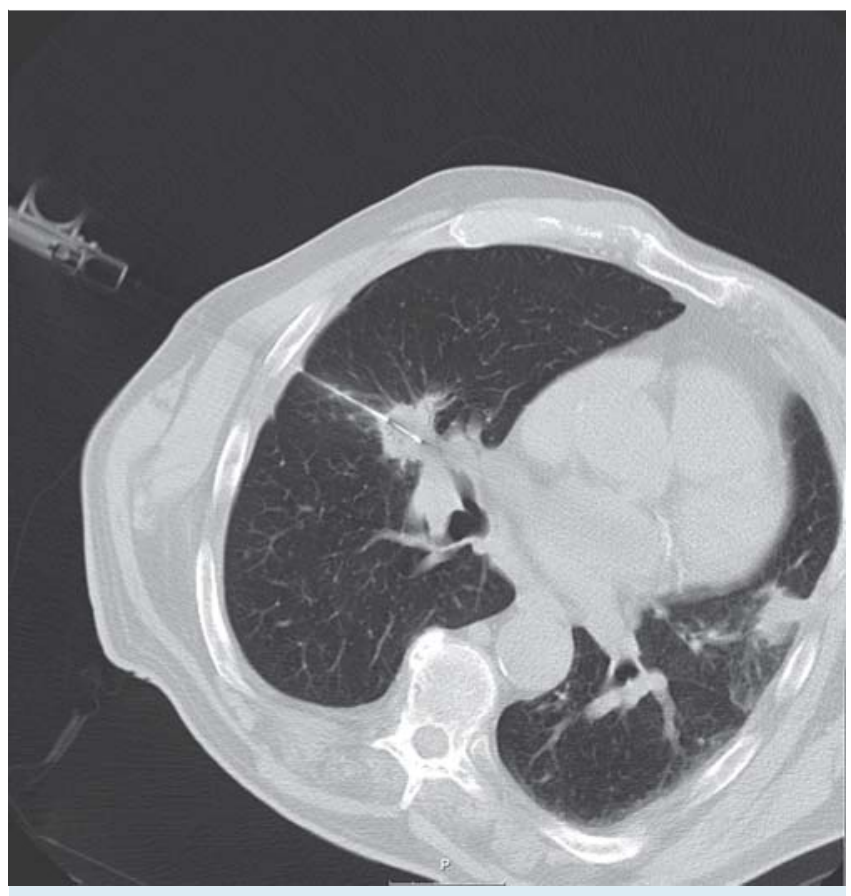

Fig. 1 Coaxial biopsy needle in a central lesion of the medial lobe. bleeding. A p.a. chest X-ray was routinely performed after $3-4$ hours and again after 24 hours.

The locations of the lesions, the diameter of the lesion to be punctured, the puncture track through the aerated lung parenchyma and the puncture angle were documented for the interventions. The puncture angle was able to be retrospectively evaluated in 471 patients and the puncture track in 545 patients. The lung function, blood clotting parameters, blood clotting medication, smoking habits, and the previously known tumor history were also documented. The histological result was verified on the basis of followup examinations or new biopsy results.

The location of the pulmonary biopsies $(n-572)$ showed that more peripheral biopsies $(n=398,69.6 \%)$ than central biopsies ( $n=174,30.4 \%$ ) were performed with 362 being in the region of the upper lobe (63.3\%). Moreover, more biopsies of the right lung ( $n=316,55.2 \%)$ than of the left lung ( $n=256,44.8 \%$ ) were performed. The lung lesions to be punctured varied with respect to their size measured at the axial transverse diameter between $0.4 \mathrm{~cm}$ and $10 \mathrm{~cm}$ ( $\bullet$ Fig. 2). The depth of the puncture needle through the aerated lung parenchyma varied between $0.0 \mathrm{~cm}$ and $12.5 \mathrm{~cm}$. The depth was less than $1 \mathrm{~cm}$ in $41.4 \%$ of the lung punctures. All complications and their subsequent treatment were documented in the course of the intervention. A differentiation was made here between minor and major complications under clinical aspects. No further intervention was performed in the case of minor complications. An additional intervention was necessary in the case of a major complication. In the Seldinger technique, a $16 \mathrm{~F}$ chest tube was placed during the examination if necessary.

The statistical evaluation of the data was performed with the statistics program "SPSS for Windows" (version 16.0, IBM, Ehningen, Germany). Nominal parameters were checked for significance with the chi-square test and linearly distributed parameters were examined by a multivariate logistic regression analysis. The effective accuracy is calculated from the sum of true positive results minus unclear positive results

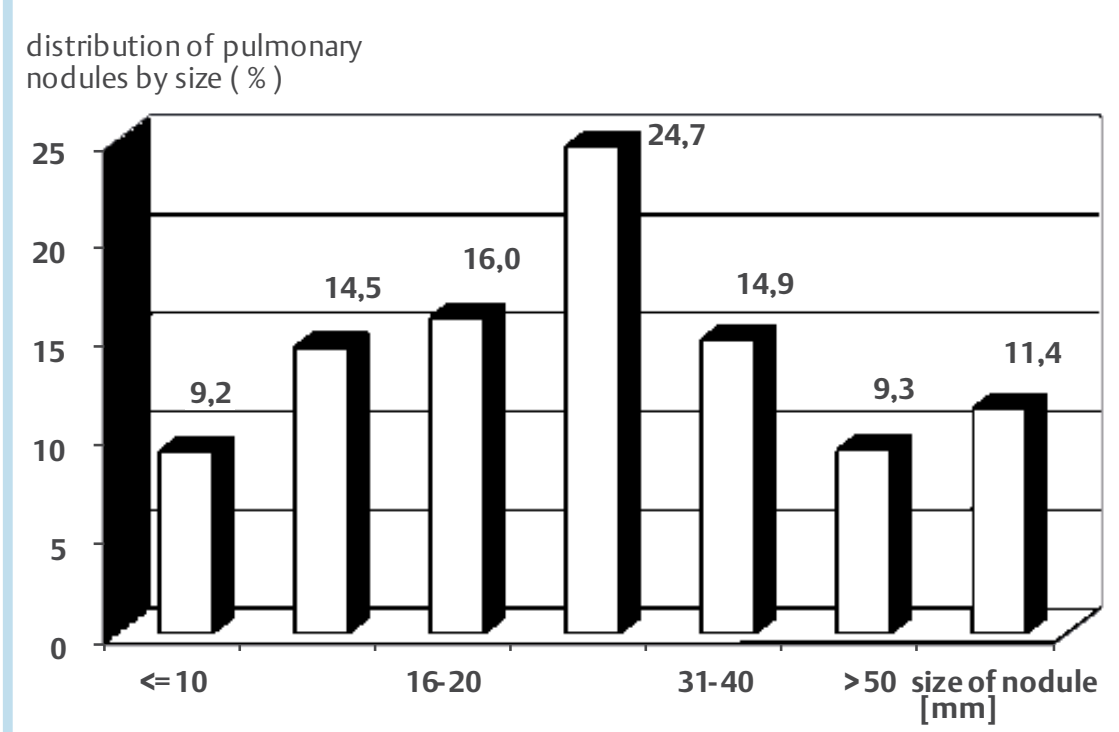

Fig. 2 Percentage distribution of pulmonary lesions according to size. 
and true negative results minus unclear negative results divided by the total number of all results [14].

\section{Results}

Pulmonary changes were biopsied under CT guidance 572 times. In 24 cases the puncture was not diagnostic with 14 false-negative results, 4 unclear positive results, 4 unclear negative results and 2 incorrect punctures that were ultimately identified via surgery as tuberculoma and hamartoma. Malignant diagnoses were correctly made in 365 cases. These included 316 primary pulmonary tumors, 42 metastases, and 7 cases in which a differentiation could not be made immunohistologically between a primary tumor and a metastasis. Benign diagnoses were made in 182 cases and were confirmed in the clinical course. The accuracy of all CT-guided core biopsies of the lung was thus $97.2 \%$, the sensitivity was $96.3 \%$, the specificity was $100 \%$, and the effective accuracy was $94.4 \%$. In all cases sufficient tissue was acquired for immunohistological differentiation of the tissue.

Table 1 Treatment-relevant complications (major) and complications not requiring treatment (minor).

\begin{tabular}{|lcclll|}
\hline type of complication & \multicolumn{2}{c}{ minor complication } & major complication \\
\cline { 2 - 5 } & number & percentage & number & percentage \\
\hline pneumothorax & 104 & $15.7 \%$ & $40^{1}$ & $6 \%$ \\
\hline hemoptysis & 37 & $5.6 \%$ & & \\
\hline interpleural bleeding & 6 & $0.9 \%$ & & \\
\hline total complications & 147 & $22.2 \%$ & 40 & $6 \%$ \\
\hline
\end{tabular}

A $16 \mathrm{~F}$ chest tube was placed in the 40 patients with a pneumothorax requiring treatment.

Table 2 Pneumothorax and puncture angle. The puncture angle could be retrospectively determined in 471 thoracocentesis procedures $(p=0.33)$.

\begin{tabular}{lccccc|}
$\begin{array}{l}\text { puncture } \\
\text { angle }\end{array}$ & punctures & $\begin{array}{l}\text { pneumothorax } \\
\text { total } \\
\mathbf{n = 1 0 9}\end{array}$ & $\begin{array}{l}\text { pneumothorax } \\
\text { with chest tube } \\
\mathbf{n = 3 5}\end{array}$ \\
\hline degree & number & no. & percentage & no. & percentage \\
\hline to $30^{\circ}$ & 63 & 10 & $15.9 \%$ & 3 & $4.8 \%$ \\
\hline to $60^{\circ}$ & 167 & 46 & $27.5 \%$ & 13 & $7.8 \%$ \\
\hline to $90^{\circ}$ & 241 & 53 & $22.0 \%$ & 19 & $7.9 \%$ \\
\hline
\end{tabular}

Complications occurred in a total of 187 cases (28.2\%) in all CT-guided biopsies $(n=664)$. An iatrogenic pneumothorax after intervention was seen in $21.7 \%$ of all cases $(n=144)$. The pneumothorax could be successfully drained via the coaxial needle in 38 cases. Follow-up was sufficient in 76 patients. A drain needed to be placed postinterventionally in only 40 patients (6\%) while it needed to be placed 14 times already during CT-guided intervention. The chest tube was placed after three hours of follow-up in 9 cases and after 6 hours of follow-up in 7 cases of progression of the pneumothorax. After 24 hours drains were necessary in another 6 patients due to progressive pneumothorax. The pneumothorax was not seen until after a time interval of 6 hours in 2 patients and after 24 hours in another 2 patients. Slight hemoptysis or bleeding without therapeutic consequence was seen on CT in 43 patients. Further treatment-relevant complications such as an air embolism or a hematothorax did not occur during the examination time period ( $\bullet$ Table 1 ). The mortality rate was $0 \%$.

Evaluation of the patient-specific risk factors showed a pneumothorax in 82 patients with emphysema. A chest tube had to be placed in 30 cases. The core biopsy resulted in a pneumothorax in 62 patients. 10 required drainage. Thus the pneumothorax incidence was $26.2 \%$ in patients with emphysema and $17.8 \%$ in patients without emphysema. The rate of pneumothoraces requiring treatment in patients with emphysema was $9.6 \%$ and $2.8 \%$ in patients without emphysema $(\mathrm{p}=0.001)$.

The pneumothorax rate in smokers was not significantly increased $(\mathrm{p}=0.87)$.

However, 253 of 474 smokers also had pulmonary emphysema. Smokers who also had emphysema developed a pneumothorax in 72 cases (28.5\%), 26 of which required drainage (10.3\%). 32 of 221 smokers without emphysema developed a pneumothorax (14.5\%), 4 of which required drainage $(1.8 \%)$ The pneumothorax rate in smokers with emphysema was significantly increased $(p=0.001)$. Compared to patients without emphysema, the pneumothorax rate in nonsmokers with emphysema was not significantly higher $(p=0.30)$.

In the evaluation of the technical aspects of CT-guided coaxial lung biopsy, 471 interventions were able to be retrospectively investigated in relation to the puncture angle. A significant relationship between puncture angle and pneumothorax rate could not be determined $(p=0.333$, - Table 2).

In the evaluation of tumor size as a risk factor, there was a trend toward an increase in the pneumothorax risk with decreasing size $(p=0.06)$. In the case of lesions with a dia-

\begin{tabular}{|c|c|c|c|c|c|}
\hline \multirow{2}{*}{$\begin{array}{l}\text { intrapulmonary puncture } \\
\text { distance }\end{array}$} & \multirow{2}{*}{$\begin{array}{l}\text { punctures } \\
n=545 \\
\text { number }\end{array}$} & \multicolumn{2}{|c|}{$\begin{array}{l}\text { pneumothorax total } \\
n=125\end{array}$} & \multicolumn{2}{|c|}{$\begin{array}{l}\text { pneumothorax with chest tube } \\
n=37\end{array}$} \\
\hline & & no. & percentage & no. & percentage \\
\hline $0-5$ & 259 & 49 & $18.9 \%$ & 7 & $2.7 \%$ \\
\hline $6-15$ & 95 & 24 & $25.3 \%$ & 9 & $9.5 \%$ \\
\hline $16-25$ & 67 & 17 & $25.4 \%$ & 7 & $10.4 \%$ \\
\hline $26-35$ & 52 & 16 & $30.8 \%$ & 9 & $17.3 \%$ \\
\hline $36-45$ & 25 & 2 & $8.0 \%$ & 1 & $4.0 \%$ \\
\hline $46-55$ & 20 & 7 & $35.0 \%$ & 1 & $5.0 \%$ \\
\hline$>55$ & 27 & 10 & $37.0 \%$ & 3 & $11.1 \%$ \\
\hline
\end{tabular}

Table 3 Correlation between pneumothorax and intrapulmonary puncture track (usable number of thoracocentesis procedures with data regarding intrapulmonary puncture track: $\mathrm{n}=545)$. 
meter of $5 \mathrm{~cm}$ or more, a pneumothorax occurred in $17.1 \%$ of cases. The pneumothorax rate was $7.1 \%$ for lesions with a size of $4.0-4.9 \mathrm{~cm}, 17.9 \%$ for lesions with a size of $3.0-$ $3.9 \mathrm{~cm}, 27.9 \%$ for lesions with a size of $2.0-2.9 \mathrm{~cm}, 23.6 \%$ for lesions with a size of $1.0-1.9 \mathrm{~cm}$, and $6.4 \%$ for lesions smaller than $1.0 \mathrm{~cm}$.

However, the pneumothorax risk correlated significantly with the increasing length of the intrapulmonary puncture track $(p=0.0001,0$ Table 3$)$.

\section{Discussion}

\section{$\nabla$}

Based on the technical improvement of CT imaging, unclear pulmonary lesions are increasingly found and undergo lowcomplication histological clarification [15]. The diagnostic differentiation of benign lesions from lesions suspicious for malignancy as well as primary pulmonary tumors from metastases is important for further treatment planning. Immunohistochemical examinations usually allow indicative differentiation between pulmonary metastases and a primary pulmonary tumor.

CT-guided biopsy is an established method for this. As already described by other authors, our results with a sensitivity of $96.3 \%$ and a specificity of $100 \%$ for this method show high diagnostic significance [2, 16-18]. In total, only 24 of 664 CT-guided core biopsies were not diagnostic. In 5 cases, the lesion was smaller than $1 \mathrm{~cm}$ and in 9 patients it was greater than $5 \mathrm{~cm}$. In the case of the latter, the histology initially showed only necrosis or perifocal inflammation. A tuberculoma and hamartochondroma were not to be punctured on the basis of the consistency. In total, the method selected here showed excellent diagnostic accuracy. In 8 cases the pathologist could not verify a definite diagnosis despite immunohistological examination.

In comparison, an accuracy of $46-65 \%$ with a sensitivity of $70-80 \%$ for bronchoscopic, transbronchial methods is published partly due to the smaller histological samples [3, 19 , 20]. The rate of complications requiring treatment is extremely low $[19,20]$. If the peripheral lesion can be visualized under ultrasound guidance, the accuracy increases to $75 \%$ [25]. In a comparative study, cellular subtyping could be performed after transthoracic puncture in $86 \%$ of patients and after transbronchial biopsy in only $61 \%$ of patients [26]. Surgical removal of the corresponding pulmonary lesion of course has a high accuracy and often acts as diagnosis and treatment in one procedure. However, evaluation of 3733 interventions showed a mortality rate of $1.21 \%$ [4]. Intraoperative differentiation between metastasis and primary bronchial carcinoma is often not possible on the basis of frozen section preparations. However, since the surgical procedure can differ greatly between metastases and primary bronchial carcinomas, a two-stage approach may be needed due to the necessary immunohistological clarification. Tissue samples acquired under CT guidance always allowed immunohistological examination in this study so that the two-phase surgical approach could be avoided. In our opinion this was due to the fact that sufficient material was acquired with 6 core biopsies. Finally this was also the reason why different authors switched from fine-needle biopsy to core biopsy in the case of pulmonary changes [8, 9]. As in our study, a diagnostic accuracy of $94-97 \%$ could be achieved for $18 \mathrm{G}$ core biopsy needles and only of $90 \%$ for a $22 \mathrm{G}$ aspiration needle [22].

In the evaluation of the value of CT-guided lung biopsy, the development of an iatrogenic pneumothorax was considered extremely significant so that the method was often even rejected [6, 7]. It is difficult to compare the current published data since it is often based on different definitions $[1,23]$. To minimize the pneumothorax risk, smaller needle calibers tended to be selected and the biopsies were often performed as fine-needle aspiration biopsies. Very different pneumothorax rates were published. However, they were rarely linked to the success rates of the diagnosis. The bottom line is that the use of smaller needle sizes lowers the risk of pneumothorax [24]. The disadvantage of a smaller needle size is that significantly less material is acquired. However, a minimally increased risk of pneumothorax seems acceptable if better diagnosis is achieved. A moderately longer duration of the needle in the lung parenchyma in the case of multiple biopsies does not appear to result in a significant increase in the risk of pneumothorax [25].

The use of a semiautomatic technique is useful in this connection. The depth of penetration of the biopsy needle into the tumor was carefully adapted to the tumor size so that tissue situated behind the tumor was damaged to the least extent possible. The risk for the development of a pneumothorax in our study is comparable with the results of other large patient collectives in which the pneumothorax incidence was slightly above $20 \%[1,17,26]$. As in other studies, the rate of pneumothoraces requiring drainage in our collective was $6 \%[18,27]$. A reduction of this rate seems possible in that the needle is removed quickly and the patient is turned on his/her side [27]. However, the incidence of bleeding of $6.5 \%$ seems lower than the values of $20-30 \%$ in other studies $[1,2]$. We attribute this to the technique used here of adapting the penetration depth of the biopsy needle to the pulmonary lesion and thus avoiding injuries distal to the lesion. Patients were asked to breathe normally during the intervention. We did not see dislocation of the coaxial needle even in the case of examination times of 20 minutes.

It was also discussed whether intraparenchymal bleeding in the puncture channel represents a complication or results in an advantage [28]. It is not surprising that radiologically visible pulmonary emphysema could be determined as a patient-dependent risk factor with an additional risk constellation for smokers. Corresponding monitoring concepts should take this into account.

Even if the visualization of pulmonary lesions on CT fluoroscopy is better, we did not use this method because of the higher exposure for the examiner and patient and because the results with the sequential CT technique are good. The slightly worse real-time monitoring with the sequential CT technique in the case of a tension pneumothorax can be compensated at any time by the preparation of a thorax drainage set or by drainage via the coaxial needle.

In particular, technical influences on the intervention vary greatly in different publications and limit comparability [1, $2,15,29,30]$. In this study all interventions were standardized by the use of a semiautomatic, coaxial core biopsy needle with the same needle size which should simplify the interpretation of the results. Limitations of the study are the 
retrospective data collection from one center and the fact that the examinations were performed by only one radiologist. This certainly limits the transferability of the results.

\section{Summary}

CT-guided coaxial biopsy of pulmonary lesions using a semiautomatic technique is a reliable and accurate diagnostic method. The rate of complications requiring treatment is low and the sensitivity and specificity are high. Patients with emphysema and a history of smoking have a significantly higher risk of pneumothorax.

\section{References}

1 Yeow KM, Su IH, Pan KT et al. Risk factors of pneumothorax and bleeding: multivariate analysis of 660 CT-guided coaxial cutting needle lung biopsies. Chest 2004; 126: $748-754$

2 Nour-Eldin NE, Alsubhi M, Naguib NN et al. Risk factor analysis of pulmonary hemorrhage complicating CT-guided lung biopsy in coaxial and non-coaxial core biopsy techniques in 650 patients. Eur J Radiol 2014; 83: 1945-1952

3 Hsia DW, Jensen KW, Curran-Everett D et al. Diagnosis of lung nodules with peripheral/radial endobronchial ultrasound-guided transbronchial biopsy. J Bronchology Interv Pulmonol 2012; 19: 5-11

4 Linden PA, D'Amico TA, Perry Y et al. Quantifying the safety benefits of wedge resection: a society of thoracic surgery database propensitymatched analysis. Ann Thorac Surg 2014; 98: 1705-1712

5 Leyden 00. Ueber infectiöse Pneumonie. Dtsch Med Wochenschr 1883; 9: $52-53$

6 Haaga JR, Alfidi RJ. Precise biopsy localization by computed tomography. Radiology 1976; 118: 603-607

7 Manhire AR, Richardson CM, Gleeson FV. Lung biopsy guidelines - for the obedience of fools and guidance of wise men. Thorax 2003; 58: 913-914

8 Schlolaut KH, Lackner K, von Uexküll-Güldenband $V$ et al. Results and complications of CT-guided puncture biopsies with a wide-lumen puncture needle. Fortschr Röntgenstr 1987; 147: 25-32

9 Keulers P, Adam G, Günther RW. Fine needle punch biopsy of the lung. Results and complications. Radiologe 1994; 34: 576-580

10 Swerdlow DR, Thaete FL. CT-guided core biopsy of difficult lesions: a modified coaxial approach. Am J Roentgenol 1994; 163: 195-196

11 Stern EJ, Frank MS. CT of the lung in patients with pulmonary emphysema: diagnosis, quantification, and correlation with pathologic and physiologic findings. Am J Roentgenol 1994; 162: 791 - 798

12 Manhire A, Charig M, Celland C et al. Guidelines for radiologically guided lung biopsy. Thorax 2003; 58: 920-936

13 Gupta S, Wallace MJ, Cardella JF et al. Quality improvement guidelines for percutaneous needle biopsy. J Vasc Interv Radiol 2010; 21: 969 975
14 Wutke R, Schmid A, Fellner F et al. CT-guided percutaneous core biopsy: Effective accuracy, diagnostic utility and effective costs. Fortschr Röntgenstr 2001; 173: 1025-1033

15 Sox HC. Better Evidence about Screening for Lung Cancer. New England Journal of Medicine 2011; 365: 455-457

16 Schreiber G, McCrory DC. Performance characteristics of different modalities for diagnosis of suspected lung cancer: summary of published evidence. Chest 2003; 123: 115S-128S

17 Choi CM, Um SW, Yoo CG et al. Incidence and risk factors of delayed pneumothorax after transthoracic needle biopsy of the lung. Chest 2004; 126: $1516-1521$

18 Takeshita J, Masago K, Kato R et al. CT-Guided Fine-Needle Aspiration and Core Needle Biopsies of Pulmonary Lesions: A Single-Center Experience With 750 Biopsies in Japan. Am J Roentgenol 2015; 204: $29-34$

19 Ishida M, Suzuki M, Furumoto A et al. Transbronchial Biopsy Using Endobronchial. Ultrasonography with a Guide Sheath Increased the Diagnostic Yield of Peripheral Pulmonary Lesions. Intern Med 2012; 51: $455-460$

20 Varela-Lema L, Fernández-Villar A, Ruano-Ravina A. Effectiveness and safety of endobronchial ultrasound-transbronchial needle aspiration: a systematic review. Eur Respir J 2009; 33: 1156-1164

21 Albanna AS, Kasymjanova G, Robitaille C et al. Comparison of the yield of different diagnostic procedures for cellular differentiation and genetic profiling of non-small-cell lung cancer. J Thorac Oncol 2014; 9: $1120-1125$

22 Rotte $\mathrm{KH}$. CT-assisted needle biopsy in pulmonary and mediastinal space-occupying lesions. The effect of spiral CT and various biopsy needles on results. Akt Radiol 1995; 5: $136-139$

23 Williams JL, Hathaway CA, Kloster KL et al. Low power, type II errors, and other statistical problems in recent cardiovascular research. Am J Physiol 1997; 273: 487-493

24 Geraghty PR, Kee ST, McFarlane G et al. CT-guided transthoracic needle aspiration biopsy of pulmonary nodules: needle size and pneumothorax rate. Radiology 2003; 229: 475 - 481

25 Ko JP, Shepard JO, Drucker EA et al. Factors influencing pneumothorax rate at lung biopsy: are dwell time and angle of pleural puncture contributing factors? Radiology 2001; 218: 491 -496

26 Dennie CJ, Matzinger FR, Marriner JR et al. Transthoracic Needle Biopsy of the Lung: Results of Early Discharge in 506 Outpatients. Radiology 2001; 219: $247-251$

27 Kim JI, Park CM, Lee SM et al. Rapid needle-out patient-rollover approach after cone beam CT-guided lung biopsy: effect on pneumothorax rate in 1191 consecutive patients. Eur Radiol 2015, Epub ahead of print

28 De Filippo M, Saba L, Silva M et al. CT-guided biopsy of pulmonary nodules: is pulmonary hemorrhage a complication or an advantage? Diagnostic and interventional radiology 2014; 20: 421 -425

29 Wagner JM, Hinshaw JL, Lubner MG et al. CT-guided lung biopsies: pleural blood patching reduces the rate of chest tube placement for postbiopsy pneumothorax. Am J Roentgenol 2011; 197: 783 - 788

30 Wiener RS, Schwartz LM, Woloshin S et al. Population-based risk for complications after transthoracic needle lung biopsy of a pulmonary nodule: an analysis of discharge records. Annals of Internal Medicine 2011; 155: 137-144 